\title{
Ensino de Relações Espaciais de Esquerda e Direita a Participantes com Autismo e Deficiência Intelectual ${ }^{1}$
}

\author{
Elaine de Carvalho Silva \\ Nassim Chamel Elias \\ Universidade Federal de São Carlos
}

\begin{abstract}
RESUMO - O reconhecimento dos conceitos de direita-esquerda é uma evidência do desenvolvimento da noção do corpo e faz parte de um processo de lateralização simbólica. Nesse sentido, o objetivo foi ensinar respostas de ouvinte para relações espaciais de direita-esquerda envolvendo partes do corpo e verificar o uso dessas relações em um contexto diferente. Foram conduzidos dois experimentos, que se diferenciaram em função da idade e repertório de entrada dos participantes e do delineamento experimental. No primeiro, foi utilizado um delineamento do tipo A-B e os participantes foram um menino com autismo e dois jovens com deficiência intelectual. No segundo, foi utilizado o delineamento de linha de base múltipla entre participantes, que foram quatro meninos com autismo. O ensino envolveu o uso de um procedimento de instrução com múltiplos exemplares e esvanecimento de dicas (imitação, dicas gestuais, verbais e físicas). Os resultados indicaram aprendizagem das relações ensinadas e uso dessas relações em um contexto diferente (generalização). O uso de múltiplos exemplares e de esvanecimento mostraram-se promissores no ensino de relações espaciais a participantes com pouco repertório verbal.
\end{abstract}

Palavras-chaves: relações espaciais, instrução com múltiplos exemplares, esvanecimento de dicas, autismo, deficiência intelectual

\section{Teaching Left-right Spatial Relations to Individuals with Autism and Intellectual Disability}

\begin{abstract}
The recognition of the left-right concept is an evidence of the body notion development and is part of a process of symbolic lateralization. In this sense, the goal of the present study was to teach listener responses to left-right spatial relations involving body parts and to verify the use of these relations in a different context. Two experiments were conducted, which differed in terms of the age and the input repertoire of the participants and and in terms of experimental design. In the first, an A-B design was used and the participants were a boy with autism and two adolescents with intellectual disabilities. In the second, a concurrent multiple baseline design across participants was used and the participants were four boys with autism. The teaching phase involved the use of a multiple exemplar instruction (MEI) and prompt fading (imitation, gestural, verbal and physical prompts) procedure. The results indicated that the participants learned the taught relations and used those relations in a different context (generalization). The use of MEI and fading showed to be promising in teaching left-right spatial relations to participants with a small verbal repertoire.
\end{abstract}

Keywords: spatial relations, multiple exemplar instruction, prompt fading, autism, intellectual disability

Para Fonseca (1995), o reconhecimento dos conceitos de direita-esquerda é uma evidência do desenvolvimento da noção do corpo e faz parte de um processo de lateralização simbólica. Ferreira et al. (2015) afirmam que crianças com dificuldades de aprendizagem apresentam alterações motoras e que as maiores dificuldades encontradas estão nas relações temporais e espaciais.

Relações espaciais podem ser definidas como um subconjunto específico de quadros autoclíticos que se referem à compreensão (Sidman, 1994) das relações entre objetos e entre objetos e a própria pessoa no espaço (Luke, Greer, Singer-Dudek, \& Keohane, 2011) pelo uso da linguagem.

1 Apoio: Os autores agradecem à Coordenação de Aperfeiçoamento de Pessoal de Nível Superior (CAPES) pela bolsa de mestrado da primeira autora.

2 Endereço para correspondência: Departamento de Psicologia, Rodovia Washington Luís, km 235, SP-310, São Carlos, SP, Brasil. CEP: 13565905.E-mail: nassim@ufscar.br
Skinner (1957) define autoclítico como um operante verbal que está baseado em ou depende de outro operante verbal e altera o comportamento do ouvinte, como, por exemplo, quando o ouvinte responde de forma adequada ao ouvir a solicitação "Por favor, pegue a figura da esquerda".

Lee (1981) conduziu dois experimentos para verificar a aquisição de repertórios de falante e de ouvinte em que foram utilizadas relações espaciais. No Experimento 1, participaram dois meninos de 9 e 10 anos com deficiência intelectual. Os estímulos para respostas não verbais consistiam em dois objetos colocados um na frente do outro e uma instrução para colocar um objeto à esquerda ou à direita do outro. Para respostas verbais, dois objetos eram colocados um ao lado do outro e era apresentada uma pergunta sobre a localização (esquerda ou direita) de um objeto em relação ao outro. Os participantes foram ensinados inicialmente a apontar ("Aponte a xícara") ou tatear ("O que é isso?") os objetos usados no experimento. Em seguida, os participantes foram 
ensinados a ecoar frases do tipo "à esquerda do(a)<objeto>" e "à direita do(a) <objeto>". Então, um participante foi ensinado a emitir respostas de falante e o outro a emitir respostas de ouvinte e foram testados no operante não treinado. Respostas verbais consistiam em dizer, por exemplo, "à direita do livro" após a pergunta "Onde está a xícara?” e respostas não verbais consistiam em responder à instrução "Coloque a xícara à direita do livro". Os resultados indicaram que o reforçamento das respostas verbais gerou um aumento no número de respostas para os dois operantes e que o reforçamento de respostas não verbais afetou somente o repertório não verbal. Lee (1981) sugere que esses resultados implicam que o comportamento sintático do indivíduo como falante e como ouvinte constituem repertórios distintos (Skinner, 1957) que requerem treino separado mesmo que eles possam se tornar relacionados após a aquisição das topografias envolvidas. Apesar dos resultados terem indicado aprendizagem dos repertórios ensinados e emergência parcial dos repertórios não ensinados diretamente, foram necessárias as fases iniciais de treino dos nomes dos objetos.

Outros estudos (Alves \& Ribeiro, 2007; Lamarre \& Holland, 1985; Luke, Greer, Singer-Dudek, \& Keohane, 2011; Medeiros \& Bernardes, 2009) investigaram a aquisição de operantes verbais utilizando relações espaciais do tipo direita/esquerda com procedimentos de instrução com múltiplos exemplares (MEI - do inglês Multiple Exemplar Instruction). A MEI consiste em arranjar as instruções de tal maneira que reflita a rotação natural entre exposições a estímulos e a expectativa de que haja emergência de respostas diferentes a esses estímulos e pode ser conduzida, por exemplo, entre conjuntos de estímulos e entre tipos de respostas (Greer \& Ross, 2008). Segundo Cooper, Heron, e Heward (2007, p.628), MEI é uma forma de "instrução que proporciona a prática com uma variedade de topografias de resposta [múltiplos exemplares] que ajudam a garantir a aquisição de formas desejadas dessa resposta e também promove a generalização da resposta na forma de topografias não treinadas. Essa tática normalmente incorpora variações tanto de estímulos quanto de respostas".

Luke et al. (2011) testaram os efeitos da MEI na emergência de respostas de falante e ouvinte usando relações espaciais. Para as respostas de ouvinte, o experimentador apresentava uma figura ao participante e pedia para ele colocar a figura à direita/esquerda de outra figura que já estava sobre a mesa ("Coloque a flor do lado esquerdo da xícara"). Para as respostas de falante (tato), o experimentador apresentava uma figura sobre a mesa e, em seguida, colocava uma segunda figura ao lado da primeira e perguntava onde a segunda figura estava em relação à primeira ("Onde está a flor?"). Durante o treino, os participantes eram ensinados a responder como ouvinte e como falante para vários estímulos diferentes. Os participantes do Experimento 1 foram três meninos e uma menina com idades entre 5 e 7 anos e diagnóstico de Transtorno do Espectro do Autismo (TEA). Os resultados indicaram que os quatro participantes demonstraram aquisição e emergência de respostas de falante e de ouvinte para relações espaciais (acima/abaixo, esquerda/ direita) com materiais bi e tridimensionais. Segundo esses autores, há ainda pouca informação sobre as estratégias que podem gerar o uso de relações espaciais por indivíduos que não adquirem esse repertório incidentalmente.

Os artigos têm apresentado resultados promissores no ensino de relações espaciais com uso de figuras e objetos, mas vale ressaltar que foram encontrados somente quatro estudos que utilizaram relações espaciais (Alves \& Ribeiro, 2007; Lee, 1981; Luke et al., 2011; Medeiros \& Bernardes, 2009), sendo que apenas dois tiveram como participantes crianças com desenvolvimento atípico (Lee, 1981; Luke et al., 2011). Nesse sentido, são necessários mais estudos que investiguem o ensino de relações espaciais com essa população.

O uso da MEI também se mostrou eficaz como procedimento de ensino (Alves \& Ribeiro, 2007; Medeiros \& Bernardes, 2009; Luke et al., 2011). Entretanto, o que ainda parece representar uma lacuna nos estudos sobre relações espaciais dentro da Análise do Comportamento, nenhum deles ensinou ou testou os conceitos de relações espaciais para partes do corpo e não verificaram a generalização com o uso dessas relações em um contexto diferente.

Adicionalmente, conforme afirma Wilder (2011), uma preocupação comum entre crianças e adultos com TEA é a falha em seguir um comando específico, como, por exemplo, não obedecer uma instrução para iniciar ou completar uma tarefa. Nessa mesma linha, Lowenkron (1998) afirma que crianças aprendem, primeiramente, repertórios receptivos, no qual respostas verbais de outras pessoas controlam determinadas respostas. Esse repertório é tomado como uma indicação de compreensão verbal.

Portanto, o objetivo desse trabalho foi ensinar, com MEI e esvanecimento de dicas, respostas de ouvinte de seguir instruções que envolvem relações espaciais esquerda/direita para partes do corpo ("Levante o braço direito", "Toque a orelha esquerda") e verificar a generalização no uso dessas relações em um contexto diferente ("Sente na cadeira da esquerda", "Pegue o carrinho da direita") a indivíduos com desenvolvimento atípico. Foram conduzidos dois experimentos, que se diferenciaram em função da idade e repertório de entrada dos participantes e do delineamento experimental. No primeiro, foi utilizado um delineamento do tipo A-B e os participantes foram um menino com autismo e dois jovens com deficiência intelectual. No segundo, foi utilizado o delineamento de linha de base múltipla concorrente entre participantes, que foram quatro meninos com autismo.

\section{Experimento 1}

\section{Método}

Participantes. Participaram deste estudo um menino de nove anos de idade (L), e dois adolescentes com 16 anos (E e M). L tem diagnóstico de TEA, apresenta estereotipias, fala na terceira pessoa quando se refere a si mesmo e não está alfabetizado. O participante $\mathrm{E}$ tem síndrome de Down (nível moderado), tem boa compreensão verbal e consegue escrever seu nome com ajuda verbal. $M$ tem diagnóstico de Deficiência Intelectual e características autistas, não está alfabetizado e necessita de instrução verbal para realizar a 
maioria das atividades cotidianas. O critério de inclusão era que os participantes apresentassem, no máximo, 50\% de respostas corretas no pré-teste (descrito abaixo).

Local. As sessões foram conduzidas em salas da instituição especializada em que os participantes estavam matriculados. As salas mediam aproximadamente $3 \times 4 \mathrm{~m}$, possuíam temperatura amena e, durante sessões de ensino e teste, estavam presentes somente o participante e a pesquisadora.

Equipamentos e Materiais. Foi utilizado um aparelho de celular afixado num suporte para gravar as sessões, um computador portátil para apresentação da avaliação de preferência (descrita abaixo) e pequenos trechos de vídeos digitais utilizados como consequências para respostas corretas nas sessões de ensino. Folhas de sulfite com o protocolo de observação impresso e canetas foram utilizados para registro das respostas.

\section{Procedimento}

Delineamento Experimental. Foi utilizado o delineamento de sujeito único do tipo A-B (Kantowitz, Roediger, \& Elmes, 2006). O procedimento iniciou com a aplicação do teste de imitação motora e da avaliação de preferência. Em seguida, foi aplicado o pré-teste e, então, iniciaram-se as fases de ensino e sondagem, sendo que sempre que o participante alcançava o critério de desempenho para duas ações, a sessão seguinte iniciava com a aplicação da sondagem. Assim que o participante alcançava 100\% de respostas corretas na sondagem, era aplicado o pós-teste.

Teste de Imitação Motora. Cada tentativa iniciava com a instrução verbal "Faça isso" e com uma ação executada pela experimentadora (tocar o nariz, bater palmas, levantar os braços, tocar as orelhas, sentar-se na cadeira, levantar uma perna e outra alternando, virar a cabeça para um lado e para outro, colocar as mãos nos joelhos, levantar da cadeira, andar em volta da cadeira). Respostas corretas de imitação do comportamento da experimentadora eram seguidas de elogio verbal descritivo (por exemplo, "Muito bem, você tocou o nariz!"). Outras respostas foram consideradas incorretas. Havia um intervalo entre as tentativas de 5 segundos. Esse teste foi composto de um único bloco com 10 tentativas. Os elogios foram apresentados após cada resposta imitativa correta para fortalecer essa resposta e manter o participante engajado na tarefa.

Avaliação de Preferência. Foi conduzida uma avaliação de preferência utilizando o método de Escolha Forçada (Fisher et al., 1992) a fim de identificar animações ou vídeos digitais de maior preferência que foram utilizados como consequências durante as condições de ensino. Para a seleção dos itens a serem utilizados na avaliação de preferência com cada participante, a instituição enviou um recado aos pais dos participantes, solicitando a indicação de vídeos considerados de preferência dos participantes da pesquisa. Os itens indicados foram apresentados em um programa computacional desenvolvido para essa finalidade. Em cada tentativa de escolha, dois vídeos eram apresentados simultaneamente ao participante juntamente com a instrução "Escolha um". No momento em que o participante fazia a escolha, o vídeo era apresentado por $15 \mathrm{~s}$. Em seguida, um novo par era apresentado. Ao término da apresentação de todos os pares possíveis, uma hierarquia de preferência foi construída e revista a cada semana. O vídeo de alta preferência foi utilizado como consequência para respostas corretas nas fases de ensino.

Pré-Teste. Cada tentativa do pré-teste iniciava com o participante em pé em frente à experimentadora, também em pé. Após a obtenção da atenção do participante (participante olhando para a experimentadora ou para os materiais), a experimentadora forneceu uma instrução identificando um movimento, um objeto ou parte do corpo e a relação espacial. Foram apresentadas as ações de ensino (Levante o braço direito/esquerdo, Toque a orelha direita/esquerda, Mostre a mão direita/esquerda, Levante a perna direita/esquerda) e de generalização (Sente na cadeira da direita/esquerda, Levante o cartão da direita/esquerda, Pegue o carrinho da direita/esquerda).

Nas tentativas com cadeiras, a experimentadora colocou duas cadeiras, uma de cada lado e atrás do participante. Nas tentativas com cartões e carrinhos, a experimentadora disponibilizou dois cartões ou dois carrinhos de mesma cor e formato em cima de uma mesa em frente ao participante. Essas ações com materiais não fizeram parte do ensino e foram apresentadas novamente no pós-teste. Essas instruções foram apresentadas randomicamente, de maneira que a mesma parte do corpo ou objeto e a relação espacial não fossem apresentadas em tentativas consecutivas. Respostas corretas foram definidas como o participante realizando a ação solicitada em até 10 s. Outras respostas foram consideradas incorretas. Não houve consequências diferenciais.

Ensino com Múltiplos Exemplares. Os múltiplos exemplares referem-se a todas as ações de ensino utilizadas no Pré-Teste, em que direita e esquerda eram utilizadas em múltiplas ações distintas (múltiplos exemplares) até que o participante respondesse corretamente a todas as ações ensinadas e testadas. Cada tentativa de ensino iniciava com o participante em pé, em frente à experimentadora. Após obter a atenção do participante, a experimentadora forneceu uma instrução (por exemplo, "Levante o braço direito"). Respostas corretas foram definidas como o participante realizando a ação solicitada em até $10 \mathrm{~s}$ e foram seguidas de elogio verbal e da apresentação de trechos de $15 \mathrm{~s}$ do vídeo de maior preferência. Outras respostas foram consideradas incorretas. Respostas incorretas implicavam o fornecimento de dicas de imitação na tentativa seguinte (por exemplo, quando a instrução era "Levante o braço direito", a experimentadora apresentava a instrução e, simultaneamente, realizava a ação, para que este pudesse imitá-la). A mesma dica era repetida por três tentativas. Quando o participante não respondia adequadamente a esta dica (imitação), ajudas físicas e dicas gestuais eram introduzidas e esvanecidas gradualmente, da seguinte maneira: (I) ajuda física total (a experimentadora pegava a parte do corpo do participante e o ajudava a executar a ação); (II) ajuda física parcial (o mesmo procedimento anterior, porém, apenas dando início ao movimento); (III) dica gestual (apontar para a parte do corpo). A mudança de níveis de ajuda também se deu a cada três tentativas. Quando, ao mudar a dica ou o tipo de solicitação, o participante não respondia corretamente, o nível 
anterior de ajuda era reintroduzido por mais três tentativas. Nessa fase, inicialmente, cada participante foi ensinado a executar uma ação até alcance de critério (três respostas corretas consecutivas para a ação, após a instrução verbal e de forma independente, ou seja, sem a apresentação das dicas de imitação, gestuais ou físicas) e, então, a executar uma segunda ação até alcance do mesmo critério. As ações de ensino eram as mesmas do Pré-Teste. Para dois participantes (M e L), com o objetivo de facilitar a discriminação entre os lados esquerdo e direito, foi incluído o ensino alternado entre duas ações desde o início de cada bloco (uma com a instrução contendo a palavra esquerda e outra contendo a palavra direita), até que o participante alcançasse critério para as duas ações concomitantemente.

Sondagem. Cada tentativa de sondagem iniciava com o participante em pé, em frente à experimentadora. Após obter a atenção do participante, era fornecida a instrução verbal. Respostas corretas foram definidas como o participante realizando a ação solicitada em até $10 \mathrm{~s}$. Outras respostas foram consideradas incorretas. Não houve consequências diferenciais. Foram apresentadas somente as ações de ensino (as mesmas ações de ensino apresentadas no Pré-Teste). Assim que o participante apresentava, corretamente, todas as ações de ensino, era introduzido o Pós-Teste, semelhante ao Pré-Teste.

Cuidados para garantir confiabilidade dos dados e integridade do procedimento. Todas as sessões foram filmadas para registro dos dados pela experimentadora e analisadas por um segundo observador para cálculos de fidedignidade. A concordância foi calculada dividindo-se o número de concordâncias pelo número de concordâncias mais o número de discordâncias e multiplicado por 100 . Houve concordância de $100 \%$ em todas as sessões. Além disso, foi verificada também a integridade procedural, em que o comportamento da experimentadora na aplicação do procedimento foi avaliado por um observador que preencheu uma ficha com o registro desses comportamentos, em $40 \%$ das filmagens. A ficha era preenchida para cada tentativa, indicando se houve apresentação correta da instrução, apresentação correta dos materiais, ausência de dicas não programadas e intervalo entre as tentativas. Os resultados indicaram que a experimentadora realizou $90 \%$ das tentativas corretamente.

Aspectos éticos da pesquisa. $\mathrm{O}$ projeto foi submetido e aprovado pelo Comitê de Ética em Pesquisas com Seres Humanos (Parecer 851026). Após a aprovação, o projeto foi apresentado aos pais ou responsáveis dos participantes. A coleta iniciou após a leitura e assinatura do Termo de Compromisso Livre e Esclarecido. O Termo de Assentimento foi lido para os participantes que responderam positivamente fazendo um desenho que representa sua assinatura.

\section{Resultados}

No teste de imitação motora, os participantes E e M obtiveram $100 \%$ de acertos e o participante L obteve $80 \%$. A Figura 1 apresenta os desempenhos dos participantes no pré-teste, nas sessões de ensino, nas sondagens e no pós-teste. Os resultados indicam que todos os participantes aprenderam as ações ensinadas que envolviam partes do corpo e relações espaciais (barras cinzas na Figura 1) e generalizaram para

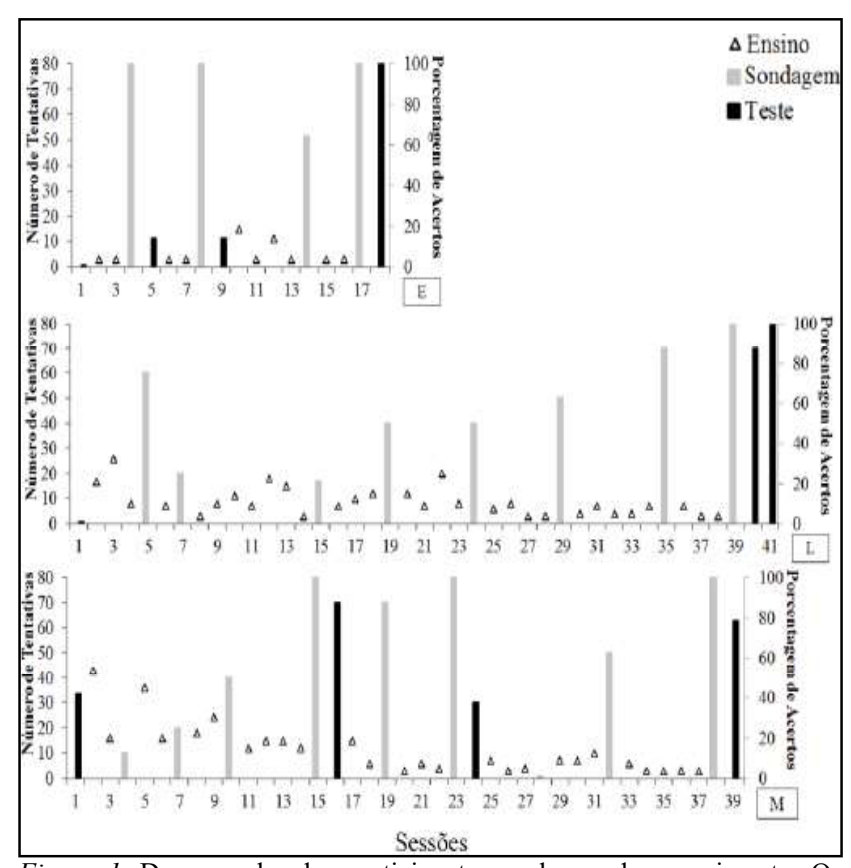

Figura 1. Desempenho dos participantes ao longo do experimento. Os triângulos indicam o número de tentativas em cada sessão. As barras pretas indicam a porcentagem de acertos nos pré e pós-testes e as barras cinzas indicam a porcentagem de acertos nas sondagens. $\mathrm{O}$ eixo vertical da esquerda apresenta os valores para as tentativas (triângulos); o eixo vertical da direita apresenta as porcentagens de acerto (barras).

as ações que envolviam objetos e materiais (barras pretas na Figura 1).

No pré-teste, E e L apresentaram $0 \%$ e $\mathrm{M}$ apresentou $42 \%$ de respostas corretas (primeira barra preta de cada participante na Figura 1). Os erros estavam relacionados, na maioria das tentativas, aos lados esquerdo e direito, sendo que os participantes executaram corretamente as ações em relação à parte do corpo e ao movimento. Os participantes E e M, que apresentaram corretamente todas as ações de ensino na primeira e quarta sondagem, respectivamente, no pós-teste que se seguiu (ver segunda barra preta dos participantes na Figura 1), inverteram os lados esquerdo e direito. A coleta com o participante $\mathrm{M}$ foi interrompida antes de alcance de $100 \%$ de respostas corretas no pós-teste, pois o participante deixou de frequentar a instituição no período final. O participante E realizou um total de 50 tentativas, o participante L, 259 tentativas e o participante M, 301 tentativas (esses valores correspondem à soma de tentativas de ensino de cada participante ao longo do experimento, representadas, na Figura 1, pelos triângulos).

A Figura 2 apresenta as porcentagens e os tipos de dicas utilizadas ao longo do procedimento. Nota-se, para todos os participantes, que o número de tentativas para alcance de critério (três respostas consecutivas corretas para cada ação) em cada bloco diminuiu e que o número e os tipos diferentes de dicas necessárias diminuíram ao longo do experimento (ver Figura 2). Por exemplo, para que o participante L respondesse corretamente nos primeiros blocos, houve uso de dicas gestuais e de imitação em mais de $70 \%$ das tentativas (duas primeiras barras do participante na Figura 2); entretanto, 
para que esse mesmo participante respondesse corretamente no último bloco em que as dicas foram apresentadas, houve uso somente de dicas gestuais em $30 \%$ das tentativas (última

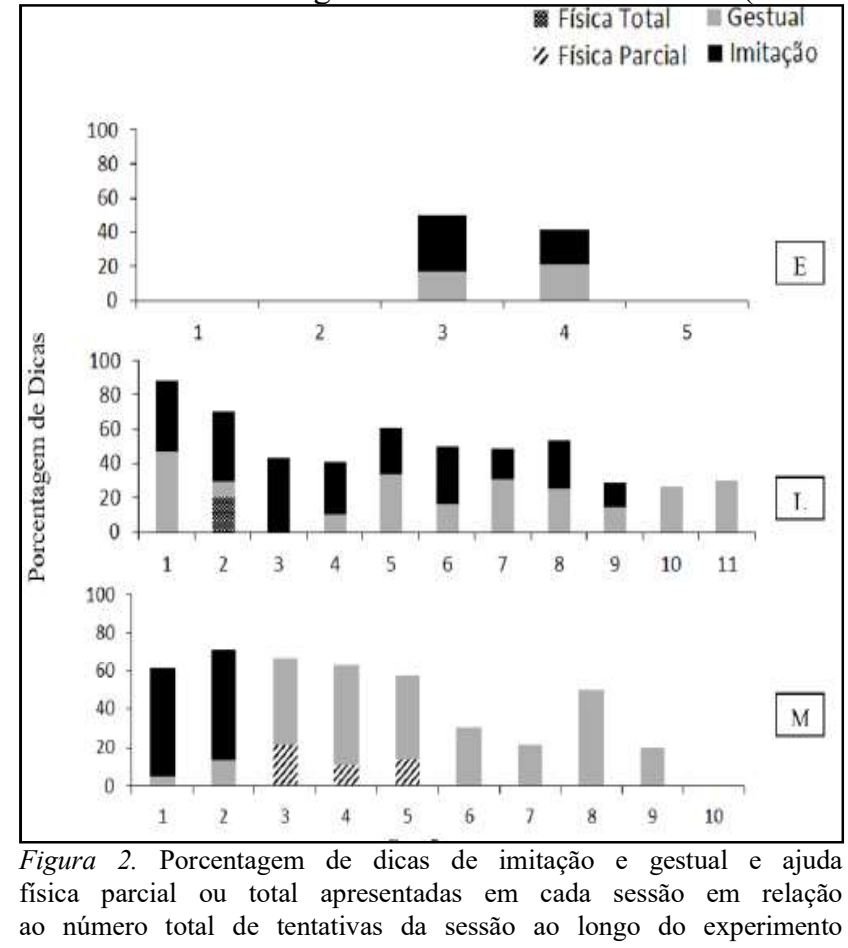

\section{Discussão}

De maneira geral, pode-se inferir que os três participantes aprenderam as ações ensinadas. Os resultados do teste de imitação motora indicam que os participantes já possuíam repertório de imitação. A diminuição no número e nos tipos de dicas necessárias ao longo do experimento indicam que o controle passou das dicas físicas, gestuais e de imitação para a instrução verbal.

$\mathrm{O}$ uso de vídeos como reforçadores, em conjunto com o uso de MEI e esvanecimento de dicas, foi eficiente na instalação de comportamentos novos, considerando que a porcentagem de acertos nas sondagens aumentou gradativamente. Outro fator facilitador na aquisição dos repertórios ensinados foi que os participantes já possuíam linguagem receptiva ou comportamento de ouvinte (Skinner, 1957), pois, conforme os dados do pré-teste, eles respondiam, mesmo que de forma incorreta, sob controle da instrução verbal. Outra característica que pode ter facilitado o aprendizado é que os participantes já respondiam sob controle de pelo menos dois componentes da instrução, o movimento e a parte do corpo ou objetos.

A inclusão de tentativas alternadas para os participantes $\mathrm{M}$ e L também parece ter influenciado na aprendizagem, pois exigia que os participantes discriminassem, entre uma tentativa e a tentativa seguinte, os componentes da instrução. Quando uma mesma instrução é apresentada repetidamente, o indivíduo pode ficar sob controle da sua última resposta, que acabou de ser reforçada, e simplesmente emiti-la novamente, sem necessariamente atentar para a instrução.

Apesar dos resultados promissores, esse experimento utilizou um delineamento do tipo A-B que, entre os delineamentos de sujeito único, é o mais passível de erros e pode ser substituído, por exemplo, por um delineamento de linha de base múltipla (Kantowitz et al., 2006). Adicionalmente, os participantes já possuíam um repertório inicial de ouvinte que pode ter facilitado o seu aprendizado. Portanto, foi realizado o Experimento 2, utilizando o delineamento de linha de base múltipla entre participantes, que tinham uma idade média mais baixa e desempenho menor no teste de imitação motora.

\section{Experimento 2}

\section{Método}

Participantes. Participaram deste estudo quatro meninos (A, D, F, K) com diagnóstico de TEA, na faixa etária de 10 a 12 anos. De acordo com declaração médica e avaliação multiprofissional, o participante A foi diagnosticado com autismo infantil e apresenta limitação motora por causa de um tumor no cérebro. $\mathrm{O}$ participante $\mathrm{D}$ tem diagnóstico de TEA sem outras especificações, boa compreensão verbal, mas não se comunica por meio da fala, apenas balbucia algumas palavras e faz uso de medicação para controle de hiperatividade. F tem diagnóstico de TEA e apresenta quadro psiquiátrico. $\mathrm{K}$ foi diagnosticado com TEA e Epilepsia Focal, o que lhe causa sérios problemas de comportamento, socialização e comunicação, faz uso de medicações e não apresenta repertório de fala. O critério de inclusão foi o mesmo do Experimento 1.

Local. Salas da instituição especializada em que os participantes foram recrutados.

Equipamentos e Materiais. Igual ao Experimento 1.

\section{Procedimento}

Delineamento Experimental. Foi utilizado um delineamento de linha de base múltipla concorrente (Cozby, 2014; Pollard, Higbee, Akers, \& Broadhead, 2014) entre participantes. Para atender esse delineamento, diferentemente do Experimento 1, o pré-teste era apresentado até encontrar estabilidade no responder, antes da introdução da fase de ensino. Esse delineamento preconiza que, após a intervenção ser iniciada com o primeiro participante, os outros continuam em linha de base até que o primeiro participante alcance os critérios de aprendizagem estabelecidos no estudo (Cozby, 2014); entretanto, como o tempo para atingir esse critério foi longo no primeiro experimento (aproximadamente três meses) e para não deixar os participantes muito tempo em espera, optou-se por ter uma linha de base mais extensa para cada participante, mas a introdução do ensino para um novo participante se deu antes do alcance de critério para os demais participantes, assim como foi feito no estudo de Pollard et al. (2014).

Avaliação de Preferência. Igual ao Experimento 1.

Ensino com Múltiplos Exemplares. Semelhante ao Experimento 1, em que as ações eram ensinadas de forma alternada na mesma sessão. Por exemplo, a primeira tentativa utilizava a ação "Levante o braço esquerdo", a segunda, "Toque a orelha direita", a terceira, "Levante o 
braço esquerdo", e assim por diante, até que o participante alcançasse o critério de três respostas corretas sem ajuda para cada ação.

Confiabilidade dos dados e integridade do procedimento. Igual ao Experimento 1. Houve concordância de $94 \%$ para as respostas dos participantes e $96 \%$ de aplicação correta do procedimento.

Aspectos éticos da pesquisa. Foram seguidos os mesmos passos do Experimento 1.

\section{Resultados}

No teste de imitação motora, a porcentagem de respostas corretas foram: $70 \%$ para o participante A, $60 \%$ para D, $100 \%$ para $\mathrm{F}$ e $90 \%$ para K. A Figura 3 apresenta os desempenhos dos participantes no pré-teste, nas sessões de ensino, nas sondagens e no pós-teste. Os resultados indicam que todos os participantes que concluíram o estudo (D, F e K) aprenderam as ações ensinadas que envolviam partes do corpo e relações espaciais (barras cinzas na Figura 3 ) e apresentaram melhora no desempenho do pré para o pós-teste final e generalizaram para as ações que envolviam objetos e materiais (barras pretas na Figura 3). O participante A não concluiu o estudo devido à cirurgia para retirar um tumor do cérebro. Após a cirurgia, o participante não retornou à escola. Entretanto, todos os dados obtidos com o participante A são apresentados.

No pré-teste, os participantes obtiveram de 0 a $50 \%$ de respostas corretas (barras pretas iniciais na Figura 3). Os erros estavam relacionados ao movimento, à parte do corpo

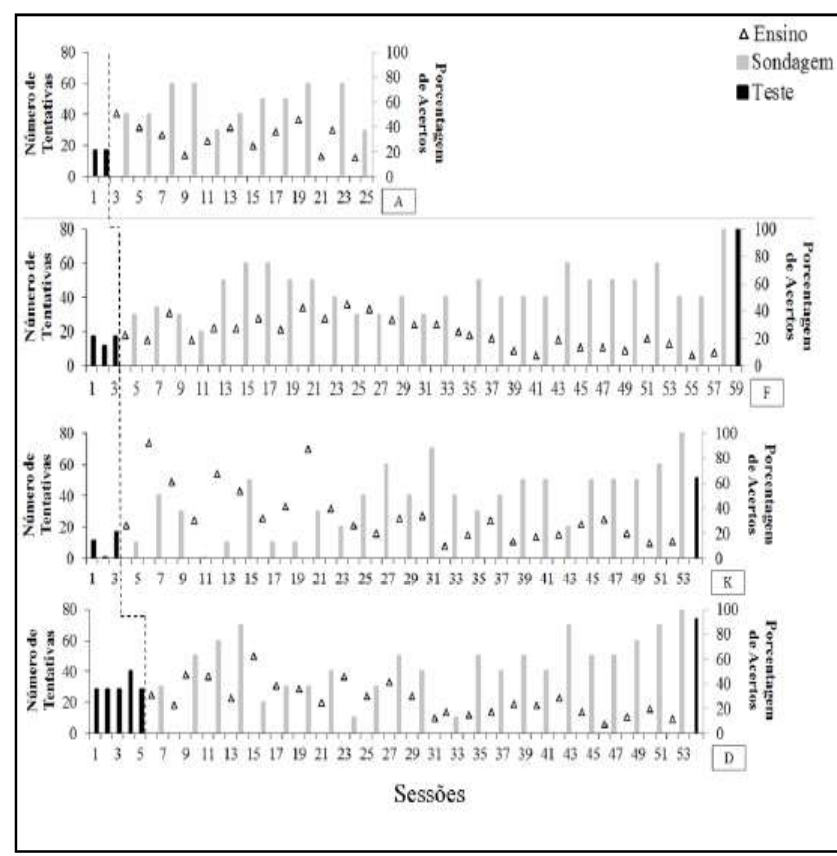

Figura 3. Desempenho dos participantes A, F, K e D ao longo do experimento. Os triângulos indicam o número de tentativas em cada sessão. As barras pretas indicam a porcentagem de acertos nos pré e pós-testes e as barras cinzas indicam a porcentagem de acertos nas sondagens. $\mathrm{O}$ eixo vertical da esquerda apresenta os valores para as tentativas (triângulos); o eixo vertical da direita apresenta as porcentagens de acerto (barras). A linha pontilhada indica a introdução do ensino e representa o delineamento de linha de base múltipla ou material e à relação espacial. O participante $\mathrm{D}$ realizou um total de 555 tentativas, o participante F, 536 tentativas e o participante K, 687 tentativas (esses valores correspondem à soma de tentativas de ensino de cada participante ao longo do experimento, representadas, na Figura 3, pelos triângulos).

A Figura 4 apresenta as porcentagens e os tipos de dicas utilizadas ao longo do procedimento por cada participante. $\mathrm{O}$ número de tentativas para alcance de critério em cada bloco e o número e os tipos diferentes de dicas necessárias diminuíram ao longo do experimento para todos os participantes (ver Figura 4). As ajudas físicas totais foram utilizadas somente com o participante $\mathrm{D}$ nos oito primeiros blocos de ensino (parte inferior das oito barras iniciais do participante D na Figura 4). Entre os participantes que concluíram o estudo, apenas $\mathrm{K}$ não alcançou desempenho superior a $90 \%$ de acertos no último pós-teste.

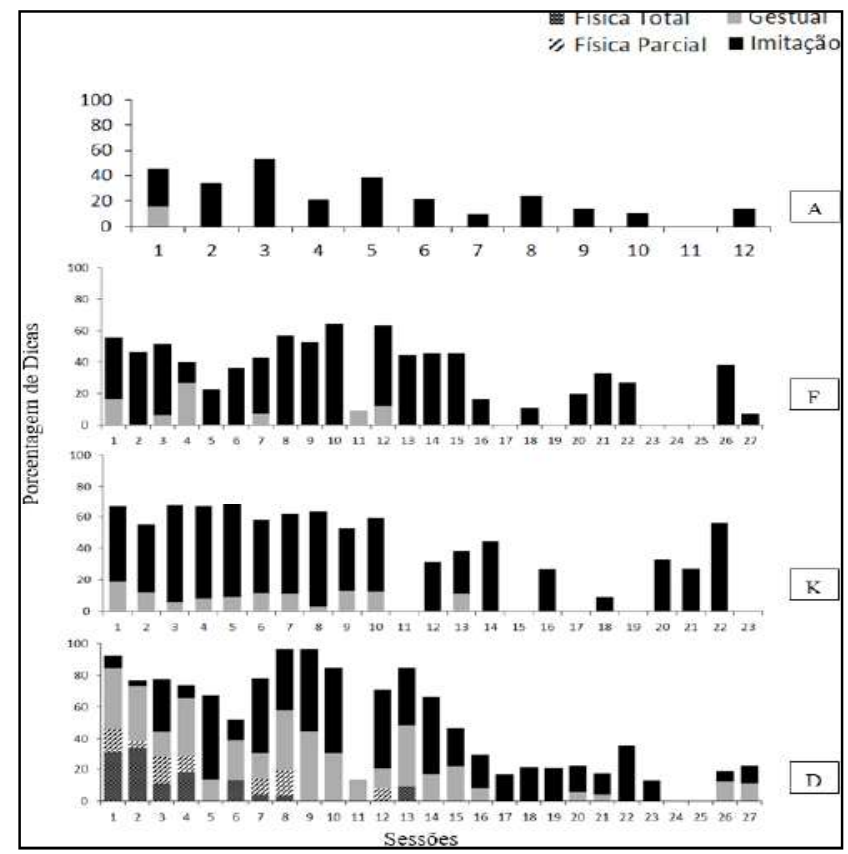

Figura 4. Porcentagem de dicas de imitação e gestual e ajuda física parcial ou total apresentadas em cada sessão em relação ao número total de tentativas da sessão ao longo do experimento

\section{Discussão}

De maneira geral, os resultados do Experimento 2 replicam os resultados do Experimento 1 e permitem inferir que os três participantes que foram submetidos a todos os passos do procedimento aprenderam as ações ensinadas. Os resultados do teste de imitação motora indicam que os participantes já possuíam repertório de imitação. A diminuição no número e nos tipos de dicas necessárias ao longo do experimento indicam que o controle passou das dicas físicas, gestuais e de imitação para a instrução verbal. O uso de vídeos como reforçadores também foi eficiente na instalação de comportamentos novos para esses participantes.

Diferentemente dos participantes do Experimento 1, os resultados do pré-teste, com erros relacionados ao movimento, à parte do corpo ou material e à relação espacial, indicam que os participantes do Experimento 2 ainda 
não apresentavam a relação entre os estímulos verbais da instrução e os estímulos correspondentes. Entretanto, podese inferir que esse repertório também foi adquirido ao longo das sessões de ensino.

Por fim, vale ressaltar que o uso do delineamento de linha de base múltipla concorrente entre participantes garante maior confiabilidade nos dados.

\section{Discussão Geral}

De maneira geral, os resultados do Experimento 2 replicam os resultados do Experimento 1, com participantes com desempenho mais baixo nos testes de imitação motora. O repertório de entrada parece ter sido uma variável relevante, pois, conforme pode ser visto nos blocos iniciais, os participantes do Experimento 2 alcançaram critério de desempenho com uma quantidade maior de tentativas, se comparados com os participantes do Experimento 1. Entretanto, o ensino foi suficiente para que os participantes dos dois experimentos passassem a discriminar as partes do corpo, os movimentos e as relações espaciais sem a necessidade do ensino de repertórios verbais de falante, diferentemente do que aconteceu no estudo de Lee (1981), em que os tatos foram ensinados antes da introdução da intervenção.

Adicionalmente, conforme pode ser visto nas Figuras 2 e 4, os participantes do Experimento 2 necessitaram de dicas por mais sessões quando comparados aos participantes do Experimento 1. A retirada gradual e consistente das dicas e ajudas teve um papel importante na instalação dos repertórios novos, não permitindo que os participantes ficassem dependentes das dicas (Martin \& Pear, 2009).

De acordo com Lovaas (1981), em condições de ensino que requerem comportamentos complexos, uma das maneiras de estimular a apresentação correta desses comportamentos é através da demonstração do professor como modelo para que o estudante o imite. A partir do momento que o estudante imita novos comportamentos sem ensino direto, ele pode aprender novas respostas, de maneira incidental, pela simples observação direta da resposta de um adulto ou par.

O uso de vídeos como reforçadores, juntamente com o procedimento de ensino com MEI e esvanecimento de dicas, foi eficiente na instalação de comportamentos novos para todos os participantes, indicando que essa pode ser uma estratégia promissora ao se planejar o ensino de indivíduos com desenvolvimento atípico. A reaplicação semanal da avaliação de preferência também foi um fator essencial nesse estudo, considerando que as preferências podem alterar ao longo do tempo, fazendo com que alguns itens percam seu valor reforçador (Fisher et al., 1992).

A inclusão de tentativas alternadas e o uso de instruções com múltiplos exemplares mostraram-se eficientes nos dois experimentos para a maioria dos participantes. Tentativas alternadas permitem que o participante faça discriminações sucessivas entre uma tentativa e a seguinte. Entretanto, como as instruções possuíam três componentes (movimento, parte do corpo e relação espacial), as discriminações nas primeiras tentativas tornaram-se muito complexas. Em novos estudos, para diminuir essa complexidade, as instruções alternadas poderiam ser diferentes somente em relação a um componente, como, por exemplo, "Levante o braço direito/esquerdo" ou "Levante a perna/braço direito" e, eventualmente, novas discriminações (com dois ou três componentes) seriam introduzidas.

Finalmente, vale ressaltar que alguns comportamentos de ouvinte, envolvendo ou não relações espaciais (por exemplo, "Coloque o relógio no braço esquerdo", "Olhe para cima para ver o avião", "Levante o braço direito quando tiver uma dúvida" ou "Olhe para baixo para não tropeçar") são essenciais para que o indivíduo apresente comportamento social e acadêmico adequado e não se exponha a condições de risco em diversas situações cotidianas. Adicionalmente, conforme sugere Ingersoll (2008), déficits em habilidades de imitação de indivíduos com TEA são prejudiciais no desenvolvimento de funções de comunicação social. A imitação, segundo o autor, tem função de aprendizado e função social, por meio da qual a criança adquire habilidades e/ou competências de comunicação, que incluem a linguagem, jogos e atenção compartilhada.

\section{Referências}

Alves, C., \& Ribeiro, A. F. (2007). Relações entre tatos e mandos durante a aquisição. Revista Brasileira de Terapia Comportamental e Cognitiva, 9(2), 289-305.

Cooper, J., Heron, T., \& Heward, W. (2007). Applied behaviour analysis. New Jersey: Pearson Education.

Cozby, P. C. (2014). Métodos de pesquisa em ciências do comportamento. São Paulo: Editora Atlas.

Ferreira, J. R. P., Rosa Neto, F, Poeta, L. S., Xavier, R. F. C., dos Santos, A. P. M., \& Medeiros, D. L. (2015). Avaliação motora em escolares com dificuldade de aprendizagem. Revista Pediatria Moderna, 51(2), 67-72.

Fisher, W. W., Piazza, C. C., Bowman, L. G., Hagopian, L. P., Owens, J. C., \& Slevin, I. (1992). A comparison of two approaches for identifying reinforcers for persons with severe and profound disabilities. Journal of Applied Behavior Analysis, 25, 491-498.

Fonseca, V. (1995). Manual de observação psicomotora Significação psiconeurológica dos fatores psicomotores. Porto Alegre: Artes Médicas.

Greer, R. D. \& Ross, D. (2008). Verbal behavior analysis: Inducing and expanding new verbal capabilities in children with language delays. Boston, MA: Pearson.

Ingersoll, B. (2008). The social role of imitation in autism: Implications for the treatment of Imitation deficits. Infants \& Young Children. 21(2), 107-119.

Kantowitz, B. H., Roediger, H. L., \& Elmes, D. G. (2006). Psicologia experimental: Psicologia para compreender pesquisa em psicologia (Tradução da $8^{\mathrm{a}}$ Ed.). São Paulo: Ed. Thomson.

Lamarre, J., \& Holland, J. G. (1985). The functional independence of mands and tacts. Journal of the Experimental Analysis of Behavior, 43(1), 5-19. Doi: 10.1901/jeab.1985.43-5

Lee, V. L. (1981). Prepositional phrases spoken and heard. Journal of the Experimental Analysis of Behavior, 35(2), 227-242. doi: 10.1901/jeab.1981.35-227 
Lovaas, O. I. (1981). Linguagem receptiva inicial. In Teaching developmentally disabled children (pp. 260 - 282). Baltimore, Maryland: University Park Press.

Lowenkron, B. (1998). Some logical functions of joint control. Journal of the Experimental Analysis of Behavior, 69, 327-354.

Luke, N., Greer, R. D., Singer-Dudek, J., \& Keohane, D. (2011). The emergence of autoclitic frames in atypically and typically developing children as a function of multiple exemplar instruction. The Analysis of Verbal Behavior, 27, 141-156. PMCID: PMC3139546

Martin, G., \& Pear, J. (2009). Modificação de comportamento: O que é e como fazer (N. C. Aguirre, Org. Trad., $8^{\mathrm{a}}$ ed.). São Paulo: Roca. (Trabalho original publicado em 2007)
Medeiros, C. A., \& Bernardes, M. C. (2009). Estabelecimento de repertório de transposição entre mandos e tatos durante a aquisição de nomes de posições. Revista Brasileira de Análise do Comportamento, 5(2), 51-68.

Pollard, J. S., Higbee, T. S., Akers, J. S., \& Brodhead, M. T. (2014). An evaluation of interactive computer training to teach instructors to implement discrete trials with children with autism. Journal of Applied Behavior Analysis, 47(4), 1-12.

Sidman, M. (1994). Equivalence relations and behavior: A research story. Boston, MA: Authors Cooperative.

Skinner, B. F. (1957). Verbal behavior. New York: AppletonCentury-Crofts.

Wilder, D. (2011). Noncompliance and oppositional behavior. Em J. $\mathrm{K}$. Luiselli (Org), Teaching and behavior support for children and adults with autism spectrum disorder: A practitioner's guide (pp. 151-158). New York: Oxford University Press.

Recebido em 09.11.2015

Primeira decisão editorial em 26.07.2016

Versão final em 15.08.2016

Aceito em 29.08.2017 